\title{
Study on Developmental Status of Tribal Children Attending Angawadis in Adilabad
}

\author{
J. Navitha ${ }^{1 *}$, P. Sreedevi ${ }^{1}$, M. Sarada Devi ${ }^{1}$ and S.L. Kameswari ${ }^{2}$ \\ ${ }^{1}$ Department of Human Development and Family studies, College of Home Science, \\ Hyderabad, India \\ ${ }^{2}$ Department of Home science Extension and Communication Management, College of Home \\ Science, Hyderabad, India \\ *Corresponding author
}

\section{A B S T R A C T}

The present research study was undertaken to study the developmental status of tribal children attending Anganwadis. A sample of 180 children in

Keywords

Developmental status,

Tribal children

development,

Anganwadi children

Developmental status

Article Info

Accepted:

07 June 2019

Available Online:

10 July 2019 the age range of 3-6 years who were attending Anganwadi centers in Adilabad district of Telangana state were selected by purposive random sampling method. Ex-post facto research design was opted for the study. Developmental assessment checklist was used for assessing the developmental status of children. Frequencies and Percentages were used to analyze the data. The findings revealed that more than half of tribal children from 3-6 years had moderate developmental status in almost all the domains of development. Developmental status in Gross motor, fine motor, Socio-emotional, Communication domains were slightly better when compared to creative expression and cognitive domains in all the age groups. The developmental status of 3-4 year old children was better compared to 4-5 and 5-6 age groups of children.

\section{Introduction}

Tribal population were most neglected and oppressed groups in India, The Integrated Child Development Services (ICDS) are the largest and most unique outreach programmes for early childhood care and development in India. It provides an opportunity for the holistic development of children from vulnerable backgrounds. The main function of preschool component of Anganwadis is to stimulate and satisfy the curiosity of the children and laying foundation for their proper physical, psychological and social development of the children.

Developmental assessment is the process of gathering information about children and it measures the child's mental, social, and physical development at each stage. It is also 
critical in making decisions regarding appropriate intervention services to cater to the developmental needs of the children.

It was observed from the review of literature that majority of the studies related to ICDS were conducted on the nutritional status, physical growth and very few studies were taken up on developmental status of children and different components of preschool education. Studies taken up on developmental status of children attending to Anganwadis revealed that cognitive and fine motor skills of children were not up to the expectations. Anganwadi workers had adequate knowledge about supplementary nutrition but very few were aware about how to conduct preschool activities in play way manner in spite of orientation and in-service training programmes (Rourkela, 2013).

It was also observed that majority of the studies related to developmental status of children focused on assessing children's performance in one or two areas of development and their interactions with one setting either teacher or parent. As development is contextual, it is important to understand the child's developmental status by studying the different areas of development. This will help the ICDS functionaries to plan effective strategies in implementing the preschool programme by addressing all these factors. Very few studies have been done in this area especially in tribal areas. Hence, an attempt was made to assess the developmental status of tribal children with the following objectives.

\section{Objectives}

To study the demographic profile of tribal children attending Anganwadis.

To assess the Developmental status of tribal children attending Anganwadis.

\section{Materials and Methods}

Based upon the nature of the research problem and objectives of the present study, Ex-post facto research design was used for the study. The sample was selected from 30 Tribal Anganwadi centers Adilabad, Telangana state. The sample comprises of 180 in the age range of 3-6 years includes 90 boys from 30 Anganwadi centers and 90 girls from 30 Anganwadi centers. A schedule was designed to collect general profile of children and Developmental assessment checklist by Maharaja Sayaji Rao university of Baroda used to collect the data, checklist consists of activities that are age appropriate for 3-4 years, 4-5years and 5-6 years in the major domains of development such as Gross motor, fine motor, socio-emotional, communication and cognitive skills, creative expression, reading, writing, and number concept respectively. The total number of items in 3-4 year age group was 98, in 4-5 years 100 items and 5-6 years 85 items, 4 point rating scoring procedure was used, Frequencies and percentages were used to analyze the data.

\section{Results and Discussion}

Table 1 clearly observed that, less than half of children were in the age range of 3-4 years, followed by 4-5 years and only few of them were in 5-6 years. With regards to the birth order, more than one third were first borns, followed by second borns and third borns and a very few were fourth, fifth and sixth borns. An equal number of boys and girls were selected for the study comprising of fifty percent for both the genders. More than half of the children were belonged to nuclear families followed by joint families and none of them had extended family. Considering the income levels, almost all of the families were belongs to low income groups and agriculture is the main occupation followed by wage labour. Similar results were found Behera (2016), 
who found that primitive tribal communities are lagging behind than the normal population with respect to their income. Gopika (2018) also revealed that, agriculture is the main occupation among scheduled tribes and agriculture sector provides them with the main means of livelihood.

Developmental status of children were measured under the different domains such as Gross motor, fine motor, socio- emotional, communication skills, cognitive skills, creative expression, reading, writing skills and number concept.

The figure 1 depicts the overall developmental status of 3-4 years of tribal children in Anganwadis. It was found that majority of the children were moderate level in domains of development like gross motor, fine motor, communication skills. Slightly more than half of the children had moderate level of socioemotional development and cognitive development. Only few of them were in high level in all the domains.

With regard to Socio-emotional and cognitive domains nearly one third of the children were in low level, which means they were poor in these two areas when compared to other areas. Similarly Neemi Devi and Sharada Devi (2013) reported that, most of the tribal children were in average developmental status and majority of the children of 4 year old children were in the average level of fine motor, gross motor, receptive communication and cognitive development, whereas majority of the children were in low average level in expressive communication and also another study by Kavitha and Pushpa Khadi (2004) revealed that 3 year old children were better in psychomotor, motor and mental development.

With regard to the overall development status of 3-4 year old children, slightly more than half of $(51 \%)$ the children were in moderate level whereas above forty percent (45\%) were in low and meager percent $(4 \%)$ of children had high developmental status.

The graph explains about the developmental status of tribal children of 4-5 years attending Anganwadis. Above Sixty percent of the children good at gross motor skills, socioemotional skills but low level in creative expression, cognitive development followed by communication skills. Which means that socio emotional and gross motor domains were slightly better when compared to other areas of development among 4-5 years. The study of Neemi Devi and Sharada Devi (2013) also revealed that, maximum of the 4-5 year old children were average category in Gross and fine motor area and low average in language domain.

Few of them were in high level in domains like gross motor, fine motor, communication skills, socio-emotional and cognitive skills and none of them were high in creative expression. With regard to the overall development status of 4-5 year old children, more than half of them $(54 \%)$ were in moderate level whereas forty $(40 \%)$ were in low and meagre percent $(6 \%)$ were in high developmental status.

The graph clearly indicates that the developmental status of tribal children of 5-6 years was very low in areas like creative expression, reading, writing and number concept, whereas in the domains like gross motor skills, fine motor, socio-emotional development children were in moderate level. Only half of the children had moderate level of communication and cognitive skills and only few of them were scored high in the areas like gross motor, communication skills, finemotor, socio-emotional and cognitive skills. This might be lack of age appropriate activities in the center, lack of competency among teachers in conducting mixed group activities (Fig. 2-5 and Table 2). 
Table.1 Demographic profile of tribal children attending Anganwadis

\begin{tabular}{|c|c|c|c|}
\hline Sl. No & Variable & Frequency N & $\begin{array}{l}\text { Percentage } \\
(\%)\end{array}$ \\
\hline 1 & \multicolumn{3}{|l|}{ Age } \\
\hline & 3-4 years & 76 & $42 \%$ \\
\hline & $4-5$ years & 78 & $44 \%$ \\
\hline & 5-6 years & 26 & $14 \%$ \\
\hline \multirow[t]{3}{*}{2} & \multicolumn{3}{|l|}{ Gender } \\
\hline & Boys & 90 & $50 \%$ \\
\hline & Girls & 90 & $50 \%$ \\
\hline \multirow[t]{7}{*}{3} & \multicolumn{3}{|l|}{ Birth order } \\
\hline & $1^{\text {st }}$ born & 72 & $40 \%$ \\
\hline & $2^{\text {nd }}$ born & 47 & $26 \%$ \\
\hline & $3^{\text {rd }}$ born & 40 & $22 \%$ \\
\hline & $4^{\text {th }}$ born & 12 & $7 \%$ \\
\hline & $5^{\text {th }}$ born & 7 & $4 \%$ \\
\hline & $6^{\text {th }}$ born & 2 & $1 \%$ \\
\hline \multirow[t]{4}{*}{4} & Income levels & & \\
\hline & Low & 179 & $99 \%$ \\
\hline & Average & 1 & $1 \%$ \\
\hline & High & -- & -- \\
\hline \multirow[t]{4}{*}{5} & Family Type & & \\
\hline & Joint & 79 & $44 \%$ \\
\hline & Nuclear & 101 & $56 \%$ \\
\hline & Extended & 0 & $0 \%$ \\
\hline \multirow[t]{6}{*}{6} & $\begin{array}{l}\text { Father } \\
\text { occupation }\end{array}$ & & \\
\hline & Farmer & 144 & $80 \%$ \\
\hline & Auto Driver & 6 & $3 \%$ \\
\hline & $\begin{array}{l}\text { Kuli (labour } \\
\text { work) }\end{array}$ & 28 & $16 \%$ \\
\hline & Tailor & 1 & $0.5 \%$ \\
\hline & Teacher & 1 & $0.5 \%$ \\
\hline
\end{tabular}


Table.2 Developmental status of tribal children attending Anganwadi centers

\begin{tabular}{|c|c|c|c|c|c|c|}
\hline \multirow{3}{*}{$\begin{array}{l}(\mathrm{N}=180) \\
\text { 3-4 years }(\mathrm{N}=76)\end{array}$} & \multicolumn{6}{|c|}{ Levels of developmental status of children } \\
\hline & \multicolumn{2}{|c|}{ High } & \multicolumn{2}{|c|}{ Moderate } & \multicolumn{2}{|c|}{ Low } \\
\hline & n & $(\%)$ & $\mathrm{n}$ & $(\%)$ & $\mathbf{n}$ & $(\%)$ \\
\hline Gross Motor & 15 & 20 & 61 & 80 & 0 & 0 \\
\hline Fine Motor & 19 & 25 & 52 & 69 & 5 & 6 \\
\hline $\begin{array}{l}\text { Socio } \\
\text { Emotional }\end{array}$ & 9 & 12 & 43 & 57 & 24 & 31 \\
\hline $\begin{array}{l}\text { Communication } \\
\text { Skills }\end{array}$ & 15 & 20 & 52 & 68 & 9 & 12 \\
\hline Cognitive Skills & 6 & 8 & 41 & 54 & 29 & 38 \\
\hline Total & 3 & 4 & 39 & 51 & 34 & 45 \\
\hline \multicolumn{7}{|c|}{ 4-5 years $(N=78)$} \\
\hline Gross Motor & 25 & 32 & 53 & 68 & 0 & 0 \\
\hline Fine Motor & 9 & 12 & 39 & 50 & 30 & 38 \\
\hline $\begin{array}{l}\text { Socio- } \\
\text { Emotional }\end{array}$ & 6 & 8 & 54 & 69 & 18 & 23 \\
\hline $\begin{array}{l}\text { Communication } \\
\text { Skills }\end{array}$ & 12 & 15 & 38 & 49 & 28 & 36 \\
\hline $\begin{array}{l}\text { Creative } \\
\text { Expression }\end{array}$ & 0 & 0 & 10 & 13 & 68 & 87 \\
\hline Cognitive Skills & 3 & 4 & 33 & 42 & 42 & 54 \\
\hline Total & 5 & 6 & 42 & 54 & 31 & 40 \\
\hline \multicolumn{7}{|c|}{ 5-6 years $(\mathrm{N}=26)$} \\
\hline Gross Motor & 10 & 38 & 14 & 54 & 2 & 8 \\
\hline Fine Motor & 3 & 12 & 16 & 62 & 7 & 27 \\
\hline $\begin{array}{l}\text { Socio } \\
\text { Emotional }\end{array}$ & 3 & 12 & 17 & 65 & 6 & 23 \\
\hline $\begin{array}{l}\text { Communication } \\
\text { Skills }\end{array}$ & 5 & 19 & 12 & 46 & 9 & 35 \\
\hline Cognitive Skills & 3 & 12 & 13 & 50 & 10 & 38 \\
\hline $\begin{array}{l}\text { Creative } \\
\text { Expression }\end{array}$ & 0 & 0 & 4 & 15 & 22 & 85 \\
\hline $\begin{array}{l}\text { Reading } \\
\text { Writing }\end{array}$ & 0 & 0 & 5 & 19 & 21 & 81 \\
\hline $\begin{array}{l}\text { Number } \\
\text { Concept }\end{array}$ & 0 & 0 & 5 & 19 & 21 & 81 \\
\hline Total & 2 & 7 & 15 & 58 & 9 & 35 \\
\hline $\begin{array}{l}\text { Total no. of } \\
\text { children in 3-6 } \\
\text { years }\end{array}$ & 10 & 6 & 96 & 53 & 74 & 41 \\
\hline
\end{tabular}


Fig.1 Developmental status of tribal children measured area wise

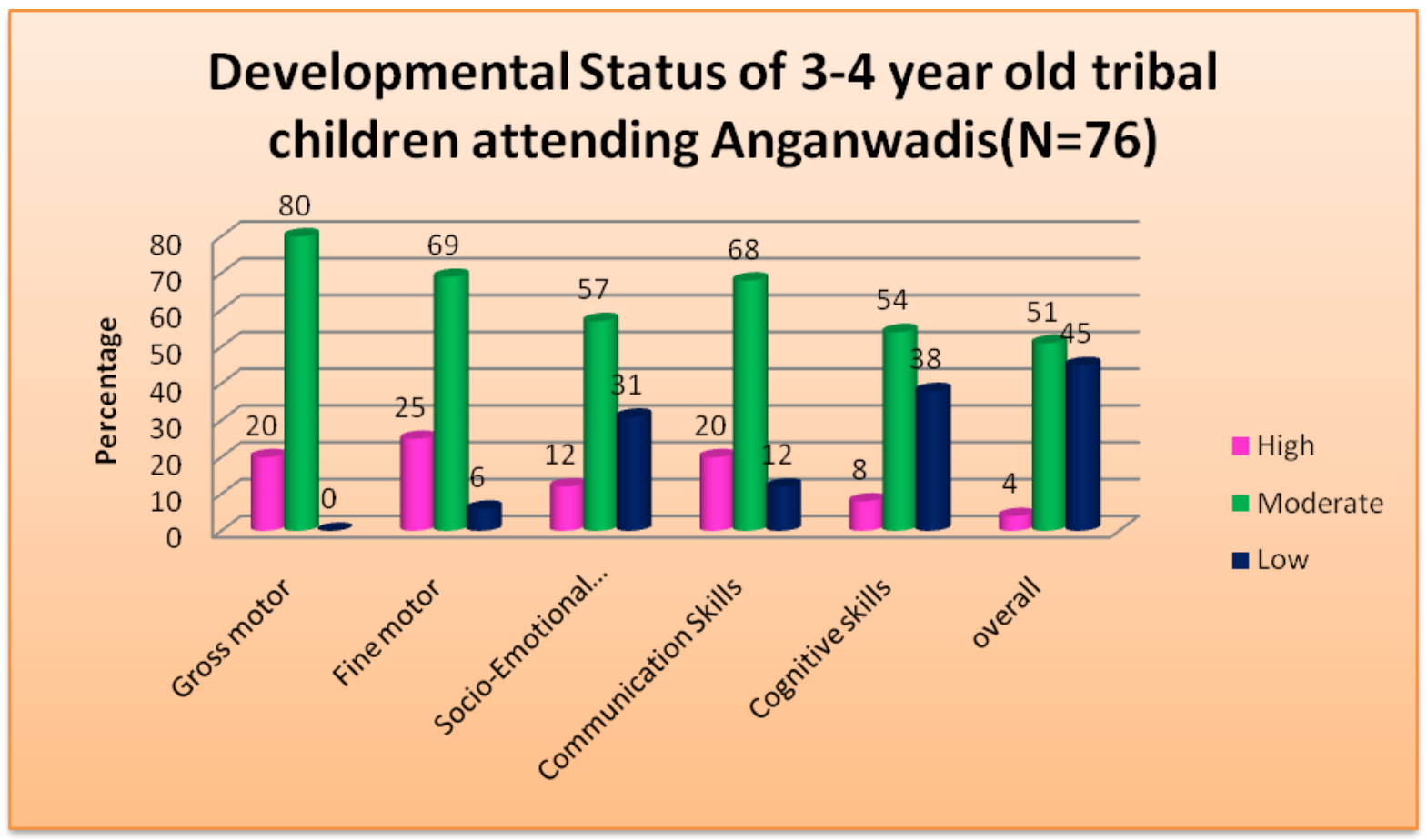

Fig.2 Developmental status of 4-5 year old tribal children attending Anganwadis

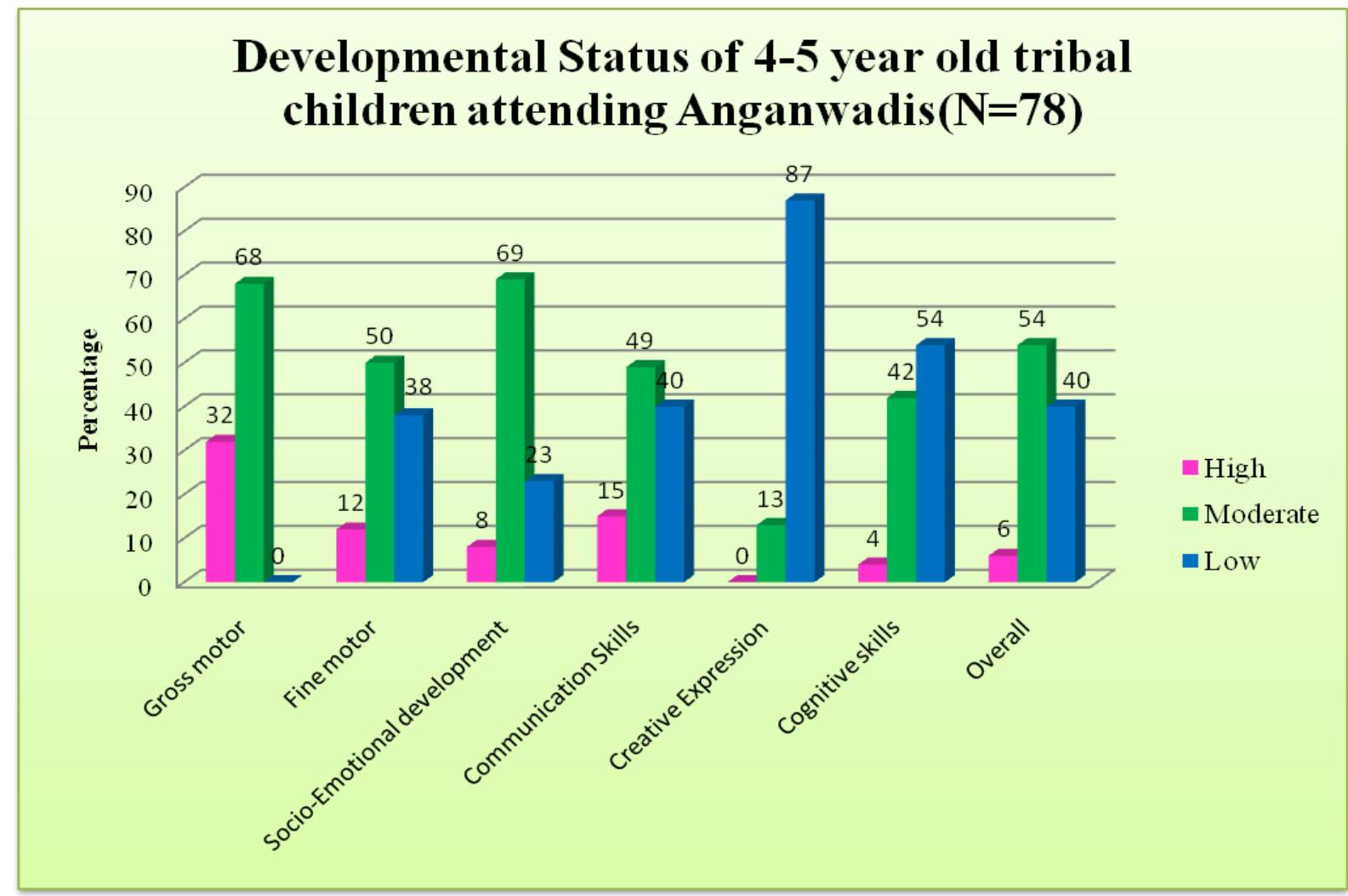


Fig.3 Developmental status of 5-6 year old tribal children attending Anganwadis

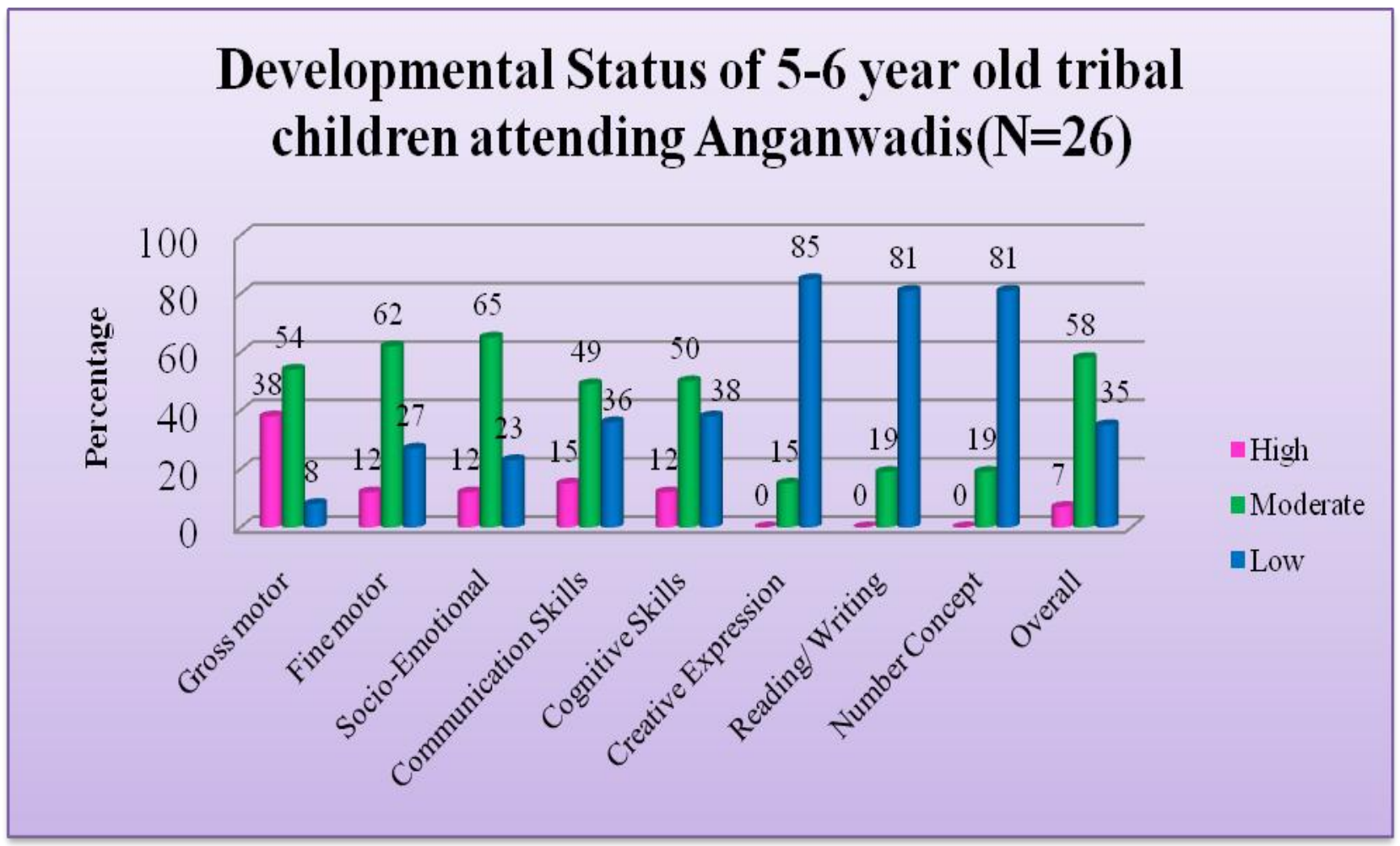

Fig.4 Developmental status of 3-6 year old tribal children attending Anganwadis

\section{Area wise developmental status of 3-6 year old tribal children attending Anganwadis $(\mathrm{N}=180)$}

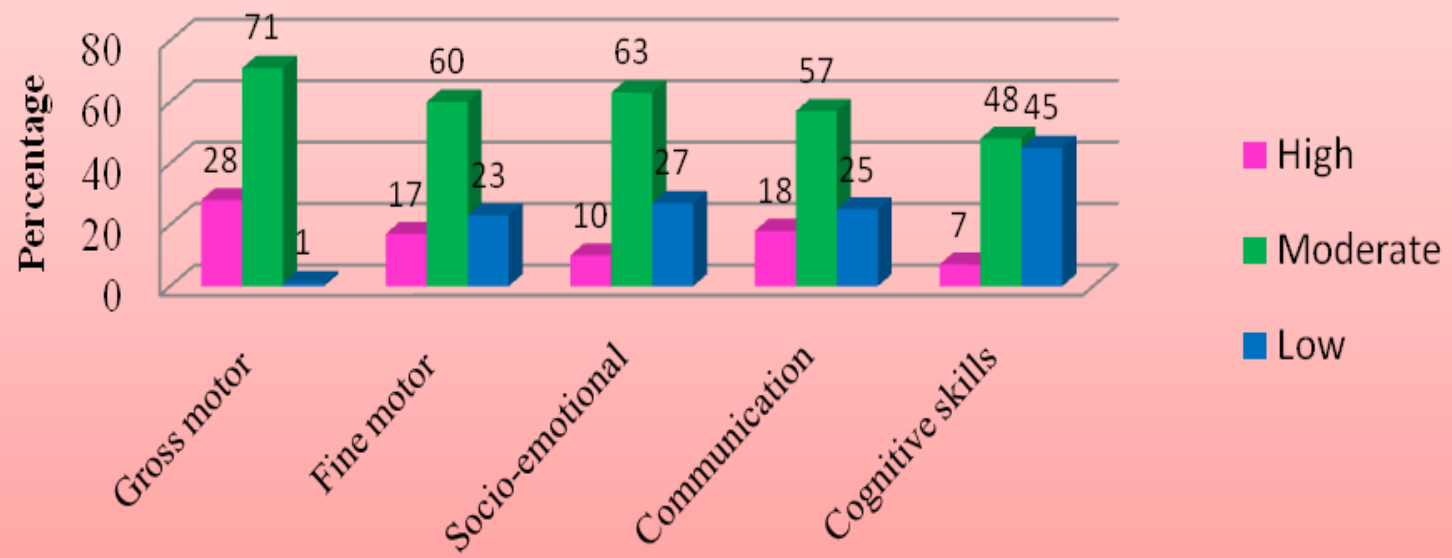


Fig.5 Developmental status of 4-5 year old tribal children attending Anganwadis

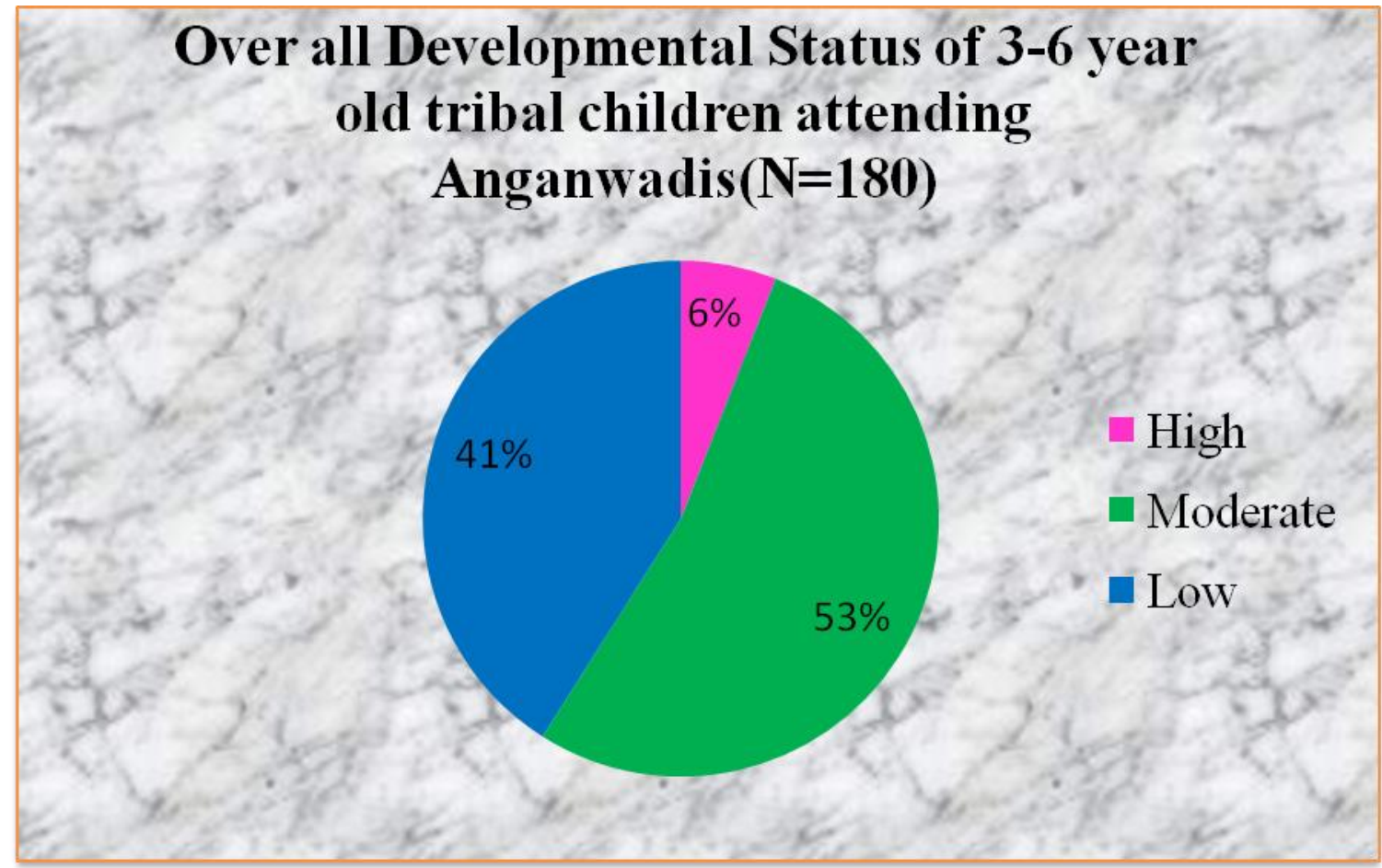

The present finding is on par with the results of Ajim premji foundation (2012-2013) which revealed that AWCs are for the most part custodial in nature and tend to miss out on the early stimulation and psycho-social interaction which is important for children under 6. AWWs are engaged in multiple initiatives, their energy is divided and attention diverted, leaving limited space and time for PSE activities and they were able to conduct the basic and fundamental activities which were not facilitative for the progress of 5-6 year old children.

With regard to the overall development status of 5-6 year old children, more than half of the $(58 \%)$ the children were in moderate level whereas one third $(35 \%)$ were in low and very few $(7 \%)$ of them were in high developmental status.

The graph clearly indicates developmental status of 3-6 year tribal children, majority of the children were average in gross motor, socio- emotional, fine motor development and more than half of the children were average in communication skills whereas less than half of children were average followed by below average in terms of cognitive skills. This might be due to less focus on age appropriate cognitive activities and language activities in the center and at home. More focus and regular implementation of activities related to gross motor, fine motor followed by socio emotional both at the center as well as at home. The results supported by J Nurs Res (2003) reported that 3-5 year old children were poor in gross motor development whereas $(60 \%)$ of the children were better in fine motor skills followed by language, personal social dimensions were above their age.

With regard to developmental status of 3-6 year old tribal children attending Anganwadis, more than half of the $(53 \%)$ children were in moderate level whereas above forty $(41 \%)$ were in moderate level and 
only very few (6\%) percent children had high developmental status. It can be inferred that only half of the tribal children were average level. More than forty percent of the children were below average level and very few children were above average level of developmental status. Similarly Neemi Devi and Sharada Devi (2013) reported that majority of 3-6 year old tribal children in Anganwadis were in low average followed by average and only few were in above average level of gross motor development.

The reasons observed for the poor development were irregularity in conducting the activities in the center, absenteeism of children, lack of balance in conducting activities for different areas of development, insufficient curriculum for age appropriate activities, poor stimulation at home for all the areas of development, more significance given on nutrition and health aspects of the children rather than conducting the preschool education both by the teacher and parents. The results supported by Arora et al., (2006) revealed that parents believe that Anganwadi center was the best place for good nutrition, health and education, their children get better nutrition and education for their overall development.

Finally it can be concluded that, the developmental status in above half of the tribal children between 3-6 years were moderate level almost all the areas. Gross motor, fine motor, socio emotional skills and communication skills were better when compared to other areas of development. Creative expression and cognitive skills were very poor when compared to other areas of development. The developmental status of 3-4 year old children was better in all the domains when compared to 4-5 and 5-6 years. Preschool activities in tribal Anganwadis should be given more focus on par with the nutrition. Anganwadi workers should be trained in conducting age appropriate activities to cater the developmental needs of children in the age range of 3-4 years, 4-5 years and 5-6 years. Teachers need to develop competency in providing stimulating learning environment to promote holistic development of the child by giving equal importance to all the areas of development. Monitoring should be strengthened in implementing the scheduled activities and using the existing teaching learning material. Thus, the present study help us to understand the developmental status of tribal children and also helps the policy makers and professionals working for the welfare of the tribal children in planning suitable training and education programmes for the Anganwadi teachers. Preschool environment plays an important role to foster and develop child's holistic development and early childhood is important because they have potential to enable children. Hence the tribal children in Anganwadi centers should be provided with structured opportunities in play way method based on their developmental level.

\section{References}

Ajim PremjI foundation (2012-2013). Review of preschool programme within the context of ICDS in Medak district, Andra Pradesh. Pg.no: 1-35

Behera M. Income and Expenditure of Particularly Vulnerable Tribal Groups of Odisha: A comparative Analysis. Journal of Economic \& Social Development, 2016; Vol-12: 146-154.

Devi. N (2013). Effect of intervention on the developmental, Nutritional and Health status of tribal children. Thesis. Pg.no: 59-63

Gopika GG. Socio-Economic Study of Kani Tribe in Trivandrum: A Case study of Njaraneeli Settlement. 2018; Thesis.

Jyothi. A (2013). Impact of ICDS on Developmental Milestones of Children 
under Five (2-5Yrs) in Telangana. International Journal of Science and Research (IJSR), 3(11), Pg.no: 11951197

Samanta. S, Basu. S.S, Haldar. D, Sarkar P.A, Saren. B.A, and Sarkar. N.G (2017). Status of early childhood education under integrated child development services scheme in bankura municipality, West Bengal. Indian Journal of Public Heath. 61(4), Pp. 261-266.

Sen, Rashmi (2010). A Study on Non-Formal Preschool Education in Selected Rural Anganwadi Centers of Chittorgarh District. Thesis.

\section{How to cite this article:}

Navitha, J., P. Sreedevi, M. Sarada Devi and Kameswari, S.L. 2019. Study on Developmental Status of Tribal Children Attending Angawadis in Adilabad.

Int.J.Curr.Microbiol.App.Sci. 8(07): 689-698. doi: https://doi.org/10.20546/ijcmas.2019.807.085 